\title{
High-efficiency orange and yellow organic light-emitting devices using platinum(II) complexes containing extended $\pi$-conjugated cyclometalated ligands as dopant materials
}

\author{
Bei-Ping Yan, Cecil C. C. Cheung, Steven C. F. Kui, V. A. L. Roy, and Chi-Ming Che ${ }^{\text {a) }}$ \\ Department of Chemistry, The University of Hong Kong, Pokfulam Road, Hong Kong SAR, China; \\ HKU-CAS Joint Laboratory on New Materials, The University of Hong Kong, Pokfulam Road, Hong Kong \\ SAR, China; and Nanotechnology Research Laboratory, The University of Hong Kong, Pokfulam \\ Road, Hong Kong SAR, China
}

Shi-Jie Xu

Department of Physics, The University of Hong Kong, Pokfulam Road, Hong Kong SAR, China

(Received 1 May 2007; accepted 13 July 2007; published online 8 August 2007)

\begin{abstract}
Two luminescent platinum(II) complexes 1 and 2 containing extended $\pi$-conjugated cyclometalated ligands have been used as dopant materials for the construction of two high-efficiency organic light-emitting devices I and II. Device I (containing dopant 1) emits orange emission and exhibits a maximum external quantum efficiency of $12.4 \%$, a maximum luminous efficiency of $32.3 \mathrm{~cd} / \mathrm{A}$, and a maximum power efficiency of $11.2 \mathrm{~lm} / \mathrm{W}$. Device II (containing dopant 2) emits yellow light and exhibits a maximum external quantum efficiency of $16.1 \%$, a maximum luminous efficiency of $51.8 \mathrm{~cd} / \mathrm{A}$, and a maximum power efficiency of $23.2 \mathrm{~lm} / \mathrm{W}$. (C) 2007 American Institute of Physics. [DOI: $10.1063 / 1.2768868]$
\end{abstract}

Bright and vibrant yellow or orange emitting materials are indispensable for the manufacture of modern multicolor visual display units. Yellow or orange colors are also important for white color displays and backlight applications, as white organic light-emitting devices (OLEDs) can often be fabricated by mixing two colors, e.g., yellow and blue, in an appropriate ratio. ${ }^{1,2}$ Orange emissions can be obtained from fluorescent laser dye [2-methyl-6-[2,3,6,7-trtrahydro-1H, $5 \mathrm{H}$-benzo[ij]quinolizin-9-yl)ethenyl]-4H-pyran-4-ylidene] propane-dinitrile, ${ }^{3}$ but the efficiency of the as-fabricated devices is low. Indeed, high-efficiency yellow or orange OLEDs can be fabricated by using phosphor-sensitized fluorescence, ${ }^{4}$ but this method involves uniformly codoping two dyes into a host material, which is a difficult process to control. In this regard, there has been considerable interest in the development of yellow or orange OLEDs that are efficient and have a suitable chromaticity. Electrophosphorescent OLEDs provide the most promising route to reach the high efficiency required as they are able to harness both singlet and triplet excitons generated by electrical injection. ${ }^{5}$ Thus far, red, green, and blue electrophosphorescence devices have been demonstrated by using octahedral iridium(III) complexes, ${ }^{6-10}$ square planar platinum(II) complexes, ${ }^{5,11-15}$ and other heavy-metal complexes, such as europium(III) chelates ${ }^{16,17}$ and osmium(II) diimine ${ }^{18}$ complexes, as emitting materials. However, there have been only a few published papers ${ }^{19-21}$ on electrophosphorescent yellow or orange OLEDs.

Recently, we synthesized yellow-green to orange electrophosphorescent $\mathrm{Pt}(\mathrm{II})$ complexes $\left(\mathrm{R}^{\wedge} \mathrm{C}^{\wedge} \mathrm{N}^{\wedge} \mathrm{N}\right) \mathrm{PtCl}$ containing extended $\pi$-conjugated cyclometalated ligands, ${ }^{22}$ which show strong emissions with quantum yields of up to 0.68 in $\mathrm{CH}_{2} \mathrm{Cl}_{2}$ or $\mathrm{MeCN}$ solution. In this work, we report the construction of two high-efficiency OLEDs employing

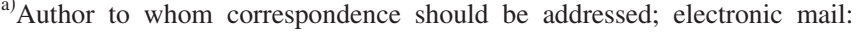
cmche@hku.hk
}

$\left(\mathrm{R}^{\wedge} \mathrm{C}^{\wedge} \mathrm{N}^{\wedge} \mathrm{N}\right) \mathrm{PtCl}$ complexes as guests, which were doped into a $4,4^{\prime}-N, N^{\prime}$-dicarbazole-biphenyl (CBP) host. For device I (containing dopant 1), a maximum external quantum efficiency of $\eta_{\text {ext }}=12.4 \%$, a maximum luminous efficiency of $\eta_{L}=32.3 \mathrm{~cd} / \mathrm{A}$, and a maximum power efficiency of $\eta_{p}$ $=11.2 \mathrm{~lm} / \mathrm{W}$ were achieved at a current density of $J$ $=3.1 \mathrm{~mA} / \mathrm{cm}^{2}(10 \mathrm{~V})$, corresponding to a brightness of $1100 \mathrm{~cd} / \mathrm{m}^{2}$. The device exhibited a maximum brightness of $21700 \mathrm{~cd} / \mathrm{m}^{2}$ (at $17.5 \mathrm{~V}$ ) and its Commission Internationale de L'Eclairage (CIE 1931) coordinates remained constant with increasing drive voltage. For device II (containing dopant 2), a maximum external quantum efficiency of $\eta_{\text {ext }}$ $=16.1 \%$, a maximum luminous efficiency of $\eta_{L}=51.8 \mathrm{~cd} / \mathrm{A}$, and a maximum power efficiency of $\eta_{p}=23.2 \mathrm{~lm} / \mathrm{W}$ were achieved at a current density of $J=0.44 \mathrm{~mA} / \mathrm{cm}^{2}(7 \mathrm{~V})$, corresponding to a brightness of $230 \mathrm{~cd} / \mathrm{m}^{2}$. The device exhibited a maximum brightness of $23500 \mathrm{~cd} / \mathrm{m}^{2}$ (at $16 \mathrm{~V}$ ) and nearly constant CIE coordinates $(x=0.44, y=0.54)$.

To maximize the performance of electrophosphorescent devices, it is necessary to choose a suitable host material and a hole-and-exciton-blocking layer (HBL). We chose CBP as the host because the photoluminescence spectrum of $\mathrm{CBP}$ overlaps with the absorption spectra of the two $\mathrm{Pt}(\mathrm{II})$ complexes used as dopants in this work. Although such spectral overlap is relevant only to the transfer of singlet states, it may, nevertheless, provide a general indication of the probability for triplet transfer. ${ }^{6}$ Furthermore, we chose 2,9dimethyl-4,7-diphenyl-1,10-phenanthroline (bathocuproine, BCP) for the HBL because of its deep highest occupied molecular orbital (HOMO) energy $(6.5 \mathrm{eV}),{ }^{15}$ which can confine both holes and excitons within the emitting layer. The hole transporting layer (HTL) was $N, N^{\prime}$-diphenyl$N, N^{\prime}$-bis(1-naphthylphenyl)-1, 1' -biphenyl-4,4'-diamine (NPB) and the electron transporting layer (ETL) was BCP. The combined use of ETL and HBL eliminates the requirement for additional electron transporting material and simplifies the overall device architecture. Device architecture and 


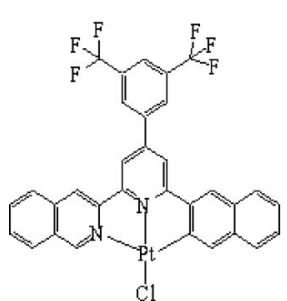

Complex 1

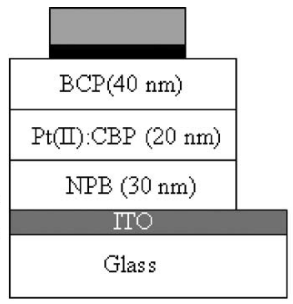

Device architecture

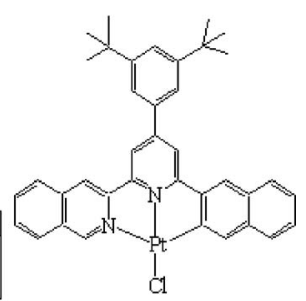

Complex 2
FIG. 1. Device architecture and molecular structure of platinum(II) complexes 1 and 2 .

chemical structure of the two Pt(II) complexes are depicted in Fig. 1. Devices I and II share the same architecture but contain different dopants.

The organic layers were deposited by thermal evaporation onto a cleaned glass substrate precoated with transparent, conductive indium tin oxide under a vacuum of $10^{-6}$ Torr. A 30-nm-thick film of NPB was first deposited as the HTL. A 20-nm-thick CBP host was then deposited, which was doped with $1-10 \mathrm{wt} \%$ of dopant 1 or 2 . The doping level was controlled by varying the relative deposition rates for CBP and Pt(II) complexes. Next, a 40-nm-thick layer of BCP was deposited as the ETL and HBL. A shadow mask with a $3 \times 3 \mathrm{~mm}^{2}$ opening was used to define the cathode, which consisted of a 0.5 -nm-thick layer of $\mathrm{LiF}$ with a 100-nm-thick aluminum cap. The electroluminescent (EL) spectra, brightness, and CIE coordinates (CIE 1931) of the OLEDs were measured with a Photo Research Inc. PR650 luminance meter. The luminance-current density-voltage characteristics were recorded simultaneously, with the EL spectra measured by combining a luminance meter with a Keithley model 2400 voltage-current source. All measurements were carried out at room temperature under ambient conditions.

To determine the optimal dopant concentration, OLEDs with different dopant concentrations were fabricated to examine the relationship between the luminous efficiency and the concentration of dopant used. For dopant 1, the optimal dopant concentration was around $5 \mathrm{wt} \%$, at which value device I exhibited a maximal luminous efficiency of $32.3 \mathrm{~cd} / \mathrm{A}$. For dopant 2, the optimal doping level was $6 \mathrm{wt} \%$, where device II showed a maximal luminous efficiency of $51.8 \mathrm{~cd} / \mathrm{A}$. Figure 2 shows the EL spectra for devices I and II at different applied voltages. Device I emitted bright orange light and the EL spectrum showed a peak maximum at $553 \mathrm{~nm}$ with a shoulder at $\lambda=594 \mathrm{~nm}$. Its EL spectra and CIE coordinates are independent of current. When the applied voltage was increased from 4 to $18 \mathrm{~V}$ (corresponding to a current density of $0.076-388.9 \mathrm{~mA} / \mathrm{cm}^{2}$ ), the CIE coordinates only changed from $(0.461,0.508)$ to $(0.474,0.507)$, indicating excellent color stability. Device II emitted yellow light and the EL spectrum had a major intensity peak at $\lambda_{\max }=540 \mathrm{~nm}$, with another intensity peak at $\lambda=580 \mathrm{~nm}$. Its EL spectra and CIE coordinates are also independent of current, only changing from $(0.423,0.546)$ to $(0.440,0.537)$ when the applied voltage was increased from 4 to $16 \mathrm{~V}$.

Figure 3 shows the external quantum efficiency $\left(\eta_{\text {ext }}\right)$ and power efficiency $\left(\eta_{P}\right)$ as a function of current density for devices I and II with optimized dopant concentration. For device I [with $5 \mathrm{wt} \%$ of dopont 1 , as shown in Fig. 3(a)]

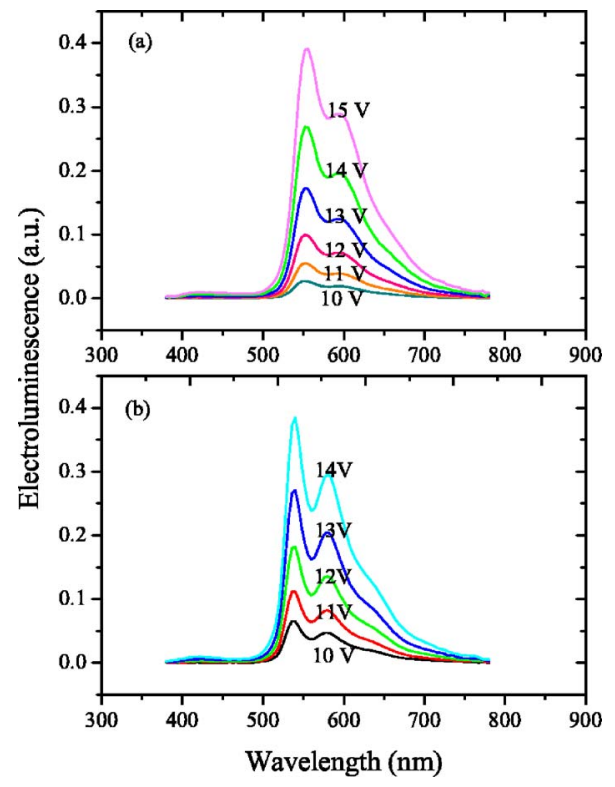

FIG. 2. (Color online) Electroluminescence spectra of devices I (a) and II (b) at different applied voltages.

maximum $\eta_{\mathrm{ext}}=12.4 \%$ and $\eta_{P}=11.2 \mathrm{~lm} / \mathrm{W}$ were achieved at a current density of $J=3.1 \mathrm{~mA} / \mathrm{cm}^{2}(10 \mathrm{~V})$. The $\eta_{\text {ext }}$ increased with increasing current at small current density $(J$ $<1 \mathrm{~mA} / \mathrm{cm}^{2}$ ), Device I exhibited a gradual decrease of $\eta_{\text {ext }}$ with increasing current, which could be attributed to triplettriplet annihilation. ${ }^{23,24}$ Even at a higher current density of $J=111 \mathrm{~mA} / \mathrm{cm}^{2}(15 \mathrm{~V})$, the efficiency of device I remained high at $\eta_{\text {ext }}=4.5 \%$ and $\eta_{P}=2.4 \mathrm{~lm} / \mathrm{W}$. For device II [with $6 \mathrm{wt} \%$ of complex 2, as shown in Fig. 3(b)], maximum $\eta_{\mathrm{ext}}=16.1 \%$ and $\eta_{P}=23.2 \mathrm{~lm} / \mathrm{W}$ were achieved at a current density of $J=0.44 \mathrm{~mA} / \mathrm{cm}^{2}(7 \mathrm{~V})$, corresponding to a brightness of $230 \mathrm{~cd} / \mathrm{m}^{2}$. At the higher current density of $J$ $=188.9 \mathrm{~mA} / \mathrm{cm}^{2}(15 \mathrm{~V})$, the device efficiency remained high at $\eta_{\mathrm{ext}}=3.6 \%, \eta_{L}=11.2 \mathrm{~cd} / \mathrm{A}$, and $\eta_{P}=2.3 \mathrm{~lm} / \mathrm{W}$. The luminous, quantum and power efficiencies of our OLEDs are superior to those of phosphor-sensitized fluorescent OLEDs, ${ }^{4}$
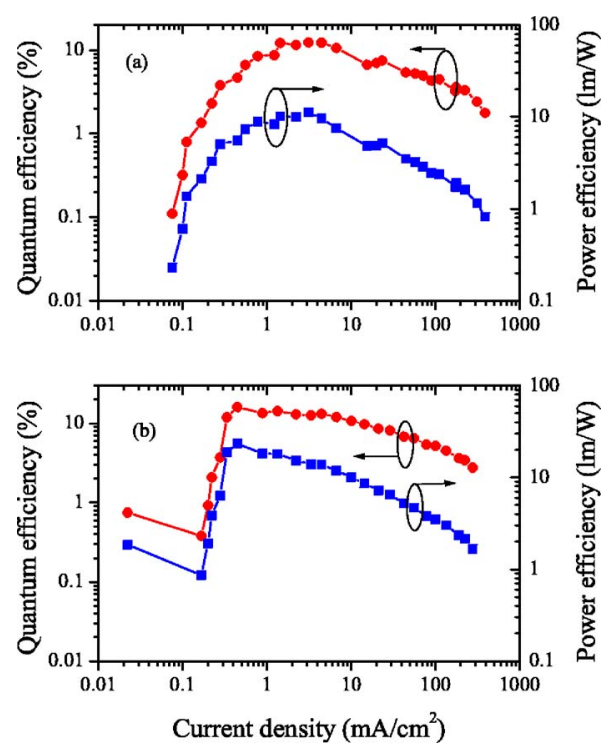

FIG. 3. (Color online) External quantum efficiency (circles) and power efficiency (squares) as a function of current density for devices I (a) and II (b) containing optimal dopant concentrations. 


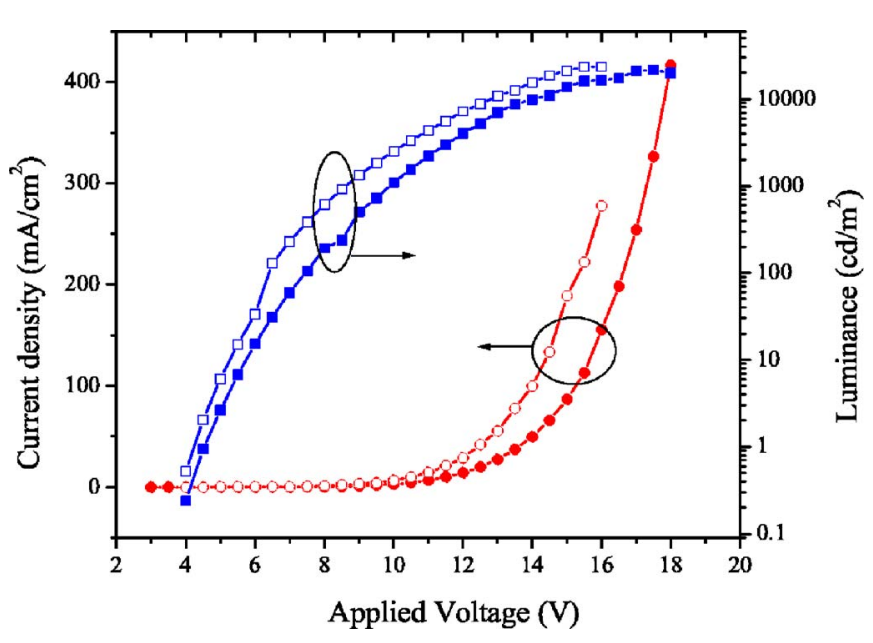

FIG. 4. (Color online) Luminance-applied voltage-current density curves of device I (solid) and device II (open). Circles stand for current density and squares represent brightness.

and two or three times higher than that reported recently for $\mathrm{Pt}(\mathrm{II})$ complexes $^{19}$ and for iridium complexes. ${ }^{20,21}$ The reason why the external quantum efficiency of device I is significantly lower than that of device II may be due to the difference in emission quantum yield of the dopants. The emission quantum yield of dopant 1 in $\mathrm{CH}_{2} \mathrm{Cl}_{2}$ solution is $0.02,{ }^{22}$ which is significantly lower than that of 0.68 of dopant 2 in the same solution.

Figure 4 shows the brightness-current density-applied voltage curves of devices I and II. For device I, the turn-on voltage of the device was $\sim 4.5 \mathrm{~V}$ for a luminance of $1 \mathrm{~cd} / \mathrm{m}^{2}$ and a maximum brightness of $21700 \mathrm{~cd} / \mathrm{m}^{2}$ was achieved at a current density of $J=326.6 \mathrm{~mA} / \mathrm{cm}^{2}(17.5 \mathrm{~V})$. The benchmark luminance of $100 \mathrm{~cd} / \mathrm{m}^{2}$ was reached at a voltage of $7.4 \mathrm{~V}$, corresponding to a current density of $0.19 \mathrm{~mA} / \mathrm{cm}^{2}$. For device II, its turn-on voltage was $\sim 4.2 \mathrm{~V}$ for $1 \mathrm{~cd} / \mathrm{m}^{2}$ and a maximum brightness of $23500 \mathrm{~cd} / \mathrm{m}^{2}$ was reached at a current density of $J=222.2 \mathrm{~mA} / \mathrm{cm}^{2}$ $(15.5 \mathrm{~V})$. The benchmark luminance of $100 \mathrm{~cd} / \mathrm{m}^{2}$ was reached at a voltage of $6.4 \mathrm{~V}$, corresponding to a current density of $0.31 \mathrm{~mA} / \mathrm{cm}^{2}$. An interesting feature could be noted from Fig. 4, where device II shows higher current densities than device I at lower voltages. This is a reproducible finding even at the same dopant concentration. This implies that both charge injection and transport behavior for dopants 1 and 2 are different. The difference is tied to respective different HOMO and lowest unoccupied molecular orbital (LUMO) levels. In this work, the HOMO and LUMO energy levels of dopants 1 and 2 were estimated from their electrochemical data, which were measured by cyclic voltammetry (CV) using $\mathrm{Ag} / \mathrm{Ag}^{+}$electrode in $10^{-4} M$ DMF solution. The HOMO and LUMO levels of dopant 1 are 5.63 and $3.14 \mathrm{eV}$, and obtained 5.38 and $3.07 \mathrm{eV}$ for dopant 2. The HOMO and LUMO levels of CBP are from Ref. 25, where they were determined by $\mathrm{CV}$ method to be 6.0 and $2.7 \mathrm{eV}$, respectively. Because the HOMO level of dopant 2 is $0.25 \mathrm{eV}$ higher than that of dopant 1, the barrier to hole injection into dopant 2 from NPB is $0.25 \mathrm{eV}$ lower than that to hole injection into dopant 1 from NPB; i.e., hole injection into dopant 2 from NPB is energetically more favorable than into dopant 1 at the same applied voltages. On the other hand, the LUMO level of dopant 1 is $0.07 \mathrm{eV}$ lower than that of dopant 2. This means that the trap effect of dopant 1 is more effective than dopant 2 in trapping electrons. Once electrons are trapped, the mobility of electrons in CBP decreases, leading to the decline of the current density at the same voltages.

In summary, we have fabricated high-efficiency orange and yellow organic light-emitting devices using phosphorescent platinum(II) complexes as dopant materials. The use of $\left[\left(\mathrm{RC}^{\wedge} \mathrm{N}^{\wedge} \mathrm{N}\right) \mathrm{PtCl}\right]$ complexes provides an entry to a family of electrophosphorescent yellow emitters.

The authors gratefully acknowledge support from the University Development Fund (Nanotechnology Research Institute, 00600009), the Strategic Research Theme on "Organic Optoelectronics," the Faculty Development Fund of the Science Faculty of The University of Hong Kong, the Research Grants Council of the HKSAR, China (HKU 7039/ 03P), the Seed Funding Programme for Basic Research (200411159167 and 200611159062), and the Innovation and Technology Commission of the Hong Kong SAR Government (ITF GHP/062/05).

${ }^{1}$ Y. S. Wu, S. W. Hwang, H. H. Chen, M. T. Lee, W. J. Shen, and C. H. Chen, Thin Solid Films 488, 265 (2005).

${ }^{2}$ S. F. Hsu, I. R. Laskar, T. M. Chen, J. W. Ma, S. W. Hwang, and C. H. Chen, Jpn. J. Appl. Phys., Part 2 45, L951 (2006).

${ }^{3}$ C. W. Tang, S. A. VanSlyke, and C. H. Chen, J. Appl. Phys. 87, 572 (1989).

${ }^{4}$ B. W. D'Andrade, M. A. Baldo, C. Adachi, J. Brooks, M. E. Thompson, and S. R. Forrest, Appl. Phys. Lett. 79, 1045 (2001).

${ }^{5}$ M. A. Baldo, D. F. O'Brien, Y. You, A. Shoustikov, S. Sibley, M. E. Thompson, and S. R. Forrest, Nature (London) 395, 151 (1998).

${ }^{6}$ M. A. Baldo, S. Lamansky, P. E. Burrows, M. E. Thompson, and S. R. Forrest, Appl. Phys. Lett. 75, 4 (1999).

${ }^{7}$ C. Adachi, M. A. Baldo, S. R. Forrest, S. Lamansky, M. E. Thompson, and R. C. Kwong, Appl. Phys. Lett. 78, 1622 (2001).

${ }^{8}$ C. Adachi, M. A. Baldo, M. E. Thompson, and S. R. Forrest, Appl. Phys. Lett. 77, 904 (2000).

${ }^{9}$ R. J. Holmes, S. R. Forrest, Y. J. Tung, R. C. Kwong, J. J. Brown, S. Garon, and M. E. Thompson, Appl. Phys. Lett. 82, 2422 (2003).

${ }^{10}$ R. J. Holmes, B. W. D'Andrade, S. R. Forrest, X. Ren, J. Li, and M. E. Thompson, Appl. Phys. Lett. 83, 3818 (2003).

${ }^{11}$ W. Lu, B. X. Mi, M. C. W. Chan, Z. Hui, N. Y. Zhu, S. T. Lee, and C. M. Che, Chem. Commun. (Cambridge) 2002, 206.

${ }^{12}$ W. Lu, B. X. Mi, M. C. W. Chan, Z. Hui, C. M. Che, N. Y. Zhu, and S. T. Lee, J. Am. Chem. Soc. 126, 4958 (2004).

${ }^{13}$ C. M. Che, S. C. Chan, H. F. Xiang, M. C. W. Chan, Y. Liu, and Y. Wang, Chem. Commun. (Cambridge) 2004, 1484.

${ }^{14}$ H. F. Xiang, S. C. Chan, K. K. Y. Wu, C. M. Che, and P. T. Lai, Chem. Commun. (Cambridge) 2005, 1408.

${ }^{15}$ D. F. O'Brien, M. A. Baldo, M. E. Thompson, and S. R. Forrest, Appl. Phys. Lett. 74, 442 (1999).

${ }^{16}$ M. D. McGehee, T. Bergstedt, C. Zhang, A. P. Saab, M. B. O’Regan, G. C. Bazan, V. I. Srdanov, and A. J. Heeger, Adv. Mater. (Weinheim, Ger.) 11, 1349 (1999).

${ }^{17}$ Z. R. Hong, C. S. Lee, S. T. Lee, W. L. Li, and S. Y. Liu, Appl. Phys. Lett. 82, 2218 (2003)

${ }^{18}$ Y. G. Ma, H. Y. Zhang, J. C. Shen, and C. M. Che, Synth. Met. 94, 245 (1998).

${ }^{19}$ I. R. Laskar, S. F. Hsu, and T. M. Chen, Polyhedron 24, 881 (2005).

${ }^{20}$ J. Wang, J. Yu, H. Lin, Y. Jiang, S. Lou, and G. Yang, Semicond. Sci. Technol. 22, 25 (2007).

${ }^{21}$ R. C. Kwong, M. R. Nugent, L. Michalski, T. Ngo, K. Rajan, Y. J. Tung, M. S. Weaver, T. X. Zhou, M. Hack, M. E. Thompson, S. R. Forrest, and J. J. Brown, Appl. Phys. Lett. 81, 162 (2002).

${ }^{22}$ S. C. F. Kui, I. H. T. Sham, C. C. C. Cheung, C. W. Ma, B. Yan, N. Zhu, and C. M. Che, Chem.-Eur. J. 13, 417 (2007).

${ }^{23}$ C. Adachi, M. A. Baldo, and S. R. Forrest, J. Appl. Phys. 87, 8049 (2000).

${ }^{24}$ M. A. Baldo, C. Adachi, and S. R. Forrest, Phys. Rev. B 62, 10967 (2000).

${ }^{25}$ M. Cocchi, D. Virgili, V. Fattori, J. A. G. Williams, and J. Kalinowski, Appl. Phys. Lett. 90, 023506 (2007). 